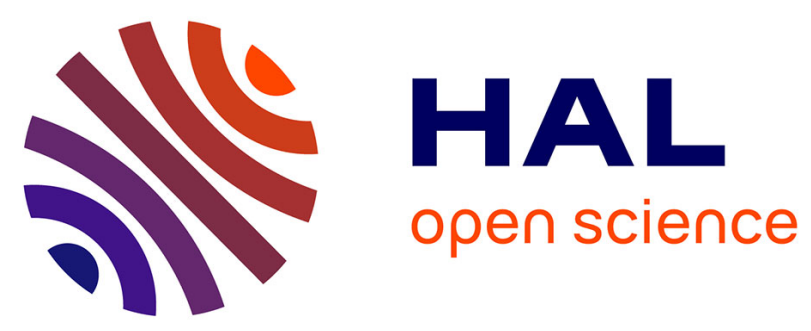

\title{
STRESSED-STRAINED STATE ANALYSIS OF MATERIAL OF PIPES BEING JOINED TOGETHER UNDER HIGH-SPEED DEFORMATION CONDITIONS
}

\author{
S. Korobov, V. Gulbin, I. Nikitin
}

\section{To cite this version:}

S. Korobov, V. Gulbin, I. Nikitin. STRESSED-STRAINED STATE ANALYSIS OF MATERIAL OF PIPES BEING JOINED TOGETHER UNDER HIGH-SPEED DEFORMATION CONDITIONS. Journal de Physique IV Proceedings, 1991, 01 (C3), pp.C3-235-C3-239. 10.1051/jp4:1991332 . jpa00250474

\section{HAL Id: jpa-00250474 https://hal.science/jpa-00250474}

Submitted on 1 Jan 1991

HAL is a multi-disciplinary open access archive for the deposit and dissemination of scientific research documents, whether they are published or not. The documents may come from teaching and research institutions in France or abroad, or from public or private research centers.
L'archive ouverte pluridisciplinaire HAL, est destinée au dépôt et à la diffusion de documents scientifiques de niveau recherche, publiés ou non, émanant des établissements d'enseignement et de recherche français ou étrangers, des laboratoires publics ou privés. 
Colloque C3, suppl. au Journal de Physique III, Vol. 1, octobre 1991

\title{
STRESSED-STRAINED STATE ANALYSIS OF MATERIAL OF PIPES BEING JOINED TOGETHER UNDER HIGH-SPEED DEFORMATION CONDITIONS
}

\author{
S. A. KOROBOV, V. N. GULBIN and I. S. NIKITIN
}

MOSCOW, USSR

\begin{abstract}
Physical model is developed and mathematical model is formulated for simulating high-speed plastic deformation process occuring in explosion-welding pipe blanks. Software is developed for realization of mathematical modelling.
\end{abstract}

\section{[NTRODUCTION}

The mathematical modelling is based on the physical model characterized by that the pressure on the exterior surface of the blank being welded in peak in character. The geometry of the physical zone of impact is defined by the fact that the dimensions of the pipes over the contact surface are much larger than their thickness. This definition eliminates the effect of end faces (elastic waves are not reflected from end faces of the pipes) and, in the final analysis, results in the mathematical model for solving two-dimensional problem, which is acceptable without sacrificing the accuracy of the solution at the ratio of the length of the pipes in the longitudinal and crosswise directions to the wall thickness not less than 40-50 and 2-3, respectively.

\section{GENERAL}

At the initial moment of time the pipes are spaced a certain distance (initial gap) from each other (Fig. I), not loaded and stationary. The internal pipe is rigidly secured, and the triangular-crosssection normal impulse load with maximum magnitude $P_{0}$, rising time $\mathcal{T}_{1}$ and falling time $\tau_{2}$ starts at a constant speed $C_{\text {over }}$ ove exterior ${ }^{1}$ surface of the pipe to being welded, $\tau_{1} \ll I$ and $\tau_{2}>\tau_{1}$. Here, $\tau_{1}=$ $\mathrm{S}_{1} / \mathrm{D}$ and $\tau_{2}=\mathrm{S}_{2} / \mathrm{D}$, where $\mathrm{D}$ is the velocity of movement of the detona-

On impact between the pipes, the expanding contact surface emerges to which the adhesion conditions are applied. Under high-speed deformation the material of the pipes behaves at the initial stage of the process as elastic with subsequent emergence of plastic components, and within the zone of contact, where stresses are large in magnitude, metal behaves as viscous fluid [1]. Therefore, the estastic-viscousplastic model has been taken for describing behaviour of the pipes.

The mathematical model of the high-speed deformation of pipes is based on the non-stationary system of first-order equations with respect to velocity $V$ and stresses tensor $\sigma_{i j} ;$ in the cylindrical sys-
tem of coordinates. 


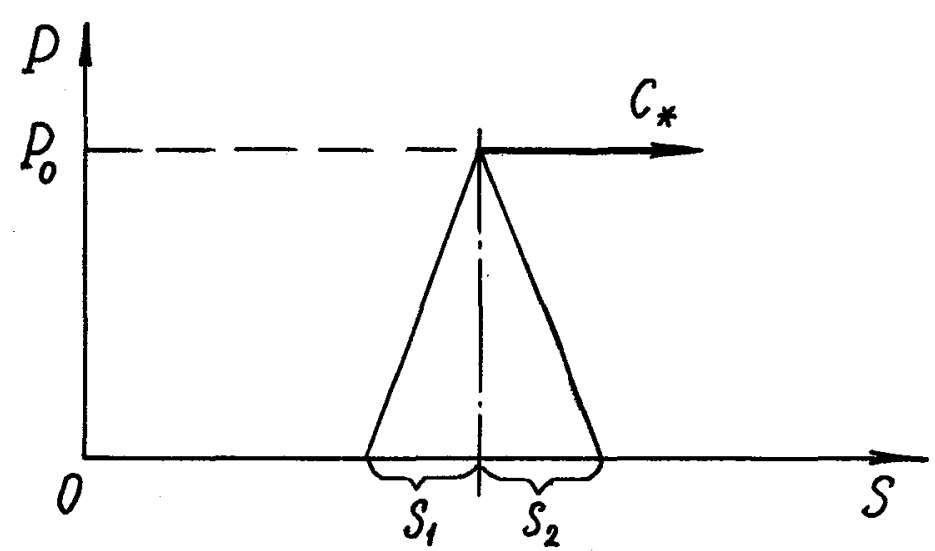

Fig. 1. External load distribution and advancement law

Mathematically, the problem shall be formulated by the following equations:

- Equation of motion

$$
\rho^{k} \frac{\partial v_{i}^{k}}{\partial t}=\frac{\partial \sigma_{i j^{k}}}{\partial x i}
$$

2. Equation of relationship between the components of stresses tensor and stresses tensor deviator

$$
\sigma_{i}=-\rho^{k} \delta_{i j}+S_{i j}{ }^{k}
$$

3. Equation of relationship between kinetic parameters and pressure.

$$
P^{k}=-K \dot{\varepsilon}_{k x}^{x}
$$

4. Principal relationships

$$
S_{i j}=2 \mu^{\kappa}\left(\dot{\xi}_{i j}^{\kappa}-\frac{1}{3} \dot{\xi}_{k \kappa}^{k} \delta_{i j}\right)-\left\langle\phi\left(J_{2}^{k}\right)\right\rangle \frac{S_{i j}{ }^{k}}{\tau^{k}}
$$

5. Equation of relationship between components of tensor deformation velocity and velocities

$$
\sigma_{i j}=\frac{1}{2}\left(\frac{\partial v_{i}}{\partial x_{j}}+\frac{\partial v_{j}}{\partial x_{i}}\right)
$$

6. Relaxation functions equations

where $i, j=1,2$,

$$
\begin{aligned}
& \phi\left(y_{2}^{k}\right)=\left(\sqrt{\frac{1}{2} S_{i j}^{k} \cdot S_{i j}{ }^{k} / m^{k}}-1\right)^{\beta}, \\
& \langle\phi\rangle=\phi(x, z)^{\beta} \cdot H(\dot{x}, z),
\end{aligned}
$$

$$
\begin{aligned}
& \mathrm{k}=1 \text { - applies to the external pipe, } \\
& \mathrm{k}=2 \text { - to the internal pipe. }
\end{aligned}
$$

\footnotetext{
$\mathrm{x}, \mathrm{z}$

The symbols in the equations are defined as follows:

$v_{i, j} \quad-\quad$ components of advancement velocity vector;

$\sigma_{i, j} \quad-\quad$ components of stresses tensor;
} 


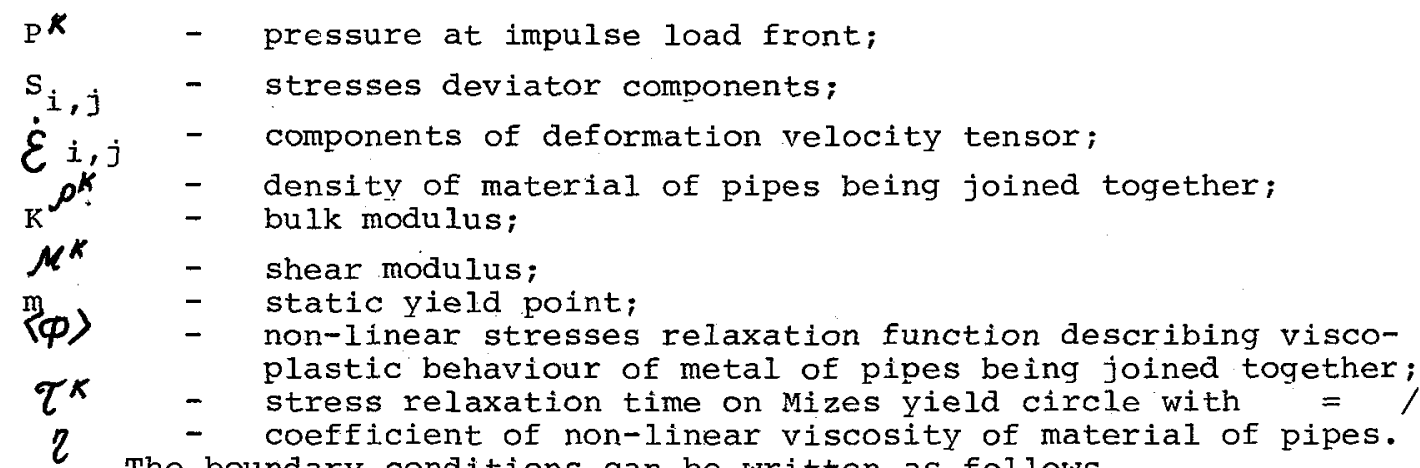

The boundary conditions can be written as follows
at $x=0$ and $x=x_{m}, \sigma_{11}=\sigma_{12}=0$

at $\tau=d^{1}, \sigma_{12}=\sigma_{22}=P\left(x-c_{x} t\right)$

at $z=-d^{2}, \quad v_{1}=0$ and $v_{2}=0$

(on outside surface of external pipe)

at $z=0$ and $x \leqslant x_{x}(t),\left[G_{12}\right]=[v i]=0$

(inside surface of internal pipe)

(pipes collision surface)

where $x_{x}(t)$ - coordinate of moving collision front;

at $z=0$ and $x_{2}(t) \leqslant x \varepsilon x_{m}, \sigma_{12}=\sigma_{22}=0$ (loaded surfaces of

where $d^{1,2}$ - the thickness of external and internal pipes, respectively

$\mathrm{x}_{\mathrm{m}}$ - the length of pipes being joined together.

The initial conditions at $t=0$ shall be

$$
\sigma_{i j}=v_{i}=0 \text {. }
$$

The set of equations $(1-5)$ is classified as semilinear hyperbolic first-order systems with highly-nonlinear free member. The values of parameter $\tau$ in the denominator of the nonlinear free member of equation (3) are very small for metal (as compared with characteristic times of running of elastic waves through the thickness of the wall of the pipes). Therefore this set of equations is also "rigid" which makes its solution rather difficult.

In the matrix form the set of equations (1-5) can be written as

$$
\frac{\partial \bar{X}}{\partial t}+A_{1} \frac{\partial \bar{X}}{\partial x}+\frac{\partial \bar{X}}{\partial z}+C(\bar{X})=0
$$

where $\mathcal{X}$ - vector column of unknown values which can be written

$$
\text { as } \bar{X}=\left(v_{1}, v_{2}, \sigma_{11}, \sigma_{12}, \sigma_{22}\right)^{\mathrm{T}} \text {. }
$$

For solution of the formulated problem use is made of the numerical method where

a) in the elastic zone $\left(\mathrm{J}_{2} \leqslant \mathrm{~m}\right)$ use is made of the explicit second accuracy order scheme predictor-corrector proposed by Maccormac [2];

b) in the viscous-plastic zone $\left(\mathrm{J}_{2}>\mathrm{m}\right)$ this scheme is supplemented with the original explicit-implicit procedure allowing solution of semi-linear system with small parameters $\widetilde{l}$ - the time of stresses relaxation on the yield circle [3];

c) the boundary points are calculated on the basis of approximation of bicharacteristic relationships for the set of equations $(1-5)$ [3]. 
The Curant's stability condition is imposed of the time step. The calculations are conducted here till. the time when the movable point of contact practically reaches the end of the pipes at $x=x_{m}$.

The calculation results are presented as the table of grid stress field $\sigma_{22}(x, z)$ and velocities $\left(V_{1}\right.$ and $\left.V_{2}\right)$ and vertical displacements of the contact surface $0 \leqslant x<{ }^{1} x$.

With the help of the graphic systềm GRAPHOR the stress and velocity fields can be shown (as isolines) on display.

The linear displacements graph $U_{2}(x) / r=0$ at $0 \leqslant x \leqslant x_{x}$ can also be shown on display, where $\mathrm{U}_{2}-$ radial displacement of the contact surface.

For the numerical solution of the problem, system (6) in the inside points of physical realm is approximated following the two-step non-central scheme (predictor-corrector) of the second accuracy order proposed by Maccormac for aerodynamic analyses.

The "predictor" step for calculation of intermediate values of the grid function $X_{i j}^{n+l}$ on the exterior layer in time (here $i$ and $j$ are the indices of the three-dimensional grid, $n$ the number of the time step) is in the form (left-hand difference in space)

$$
\frac{\bar{X}_{i j}^{n+1}-\bar{X}_{i j}^{n}}{\Delta t}=A_{1} \frac{\bar{X}_{i j}^{n}-\bar{X}_{i-1, j}^{n}}{\Delta x}+A_{2} \frac{\bar{X}_{i j}^{n}-\bar{X}_{l, j-1}^{n}}{\Delta z}+C\left(\bar{X}_{i j}^{n}\right) \text {. }
$$

The "corrector" step relates the sought-for and the intermediate values of the grid vector of the unknown values on the exterior layer (right-hand difference in space)

$$
\frac{\bar{X}_{i j}^{n+1}-\frac{1}{2}\left(\bar{X}_{i j}^{n+1}+\bar{X}_{i j}^{n}\right)}{\frac{1}{2} \Delta t}=A_{1} \frac{\bar{X}_{i+h j}^{n+1}-\bar{X}_{i j}^{n+1}}{A_{2}} \frac{\bar{X}_{i, j+1}^{n+1}-\bar{X}_{i j}^{n+1}}{\Delta Z}+C\left(\bar{X}_{i j}^{n}\right) \text {. }
$$

If the Curant's stability conditions are satisfied the stability scheme on the square grid in the form

$$
\Delta t=q \frac{\sqrt{2}}{2} \frac{\Delta x}{c \max },
$$

where $q \quad l$ is the Curant's number.

on the non-square grid the restraint on step is selected geometrically in conformity with the Curant-Dridrichs-Levi conditions (4) and is in the form

$$
C_{\max } \Delta t=q \frac{\sqrt{x^{2}+\Delta r^{2}}}{2}
$$

In the viscoplastic zone ( $\left.s_{i j} \cdot s_{i j} \geqslant 2 \mathrm{~m}^{2}\right)$ this scheme at small values of $\tau<\Delta t$ becomes unstable. In this case the equations for deviators are approximated by the implicit scheme

$$
\frac{S_{i j}^{n+1}-S_{i j}^{n}}{\Delta t}=2 \mu V_{i j}{ }^{n+1}-\left\langle\phi\left(J_{2}{ }^{n+1}\right)\right\rangle \cdot \frac{S_{i j}{ }^{n+1}}{\tau} \text {. }
$$

From this the corrective procedure follows for deviator when the Mizes' yield conditions are not satisfied:

$$
\begin{gathered}
S_{i j}^{n+1}=\frac{S_{i j}^{n}+2 \mu \Delta \varepsilon_{i j}^{n+1}}{\Gamma}\left[1+(\Gamma-1)^{1 / \beta} \cdot \delta^{\prime} / \beta\right], \\
\text { where } \Gamma=\sqrt{\frac{1}{2}\left(S_{i j}^{n}+2 \mu \Delta \varepsilon_{i j}^{n+1}\right)\left(S_{i j}^{n}+2 \mu \Delta \varepsilon_{i j}^{n+1}\right)}, \quad \text { - intensity of } \\
\delta=T / \Delta t<1 .
\end{gathered}
$$

Correction of deviators for retaining the second order of accuracy is use both on the "predictor" and "corrector" of the principal numeric scheme. 
In calculating the boundary points use has been made of the bicharacteristics relationships of the directions lying in the plane $(x, r)$ in calculation of the boundary $x=$ const or in the plane $(\boldsymbol{r}, t)$ in calculation of the boundary $\boldsymbol{\tau}=$ const.

In the former case these relationships are in the form

$$
\left(\ell_{A}^{0} \bar{X}\right), t+C_{A}^{(1)}\left(\ell_{A}^{(1)} \bar{X}\right)_{, x}=\left(\ell_{A}^{0} B \bar{X}\right)_{, z}+\left(\ell_{A}^{(0)} C\right) \text {, }
$$

where:

$$
\begin{aligned}
& \ell_{A}^{(}-\text {the i-th left-hand eigenvector of the matrix } A \text {, and } \\
& C_{A}^{O}-\text { its i-th eigenvalue. Here: } \\
& \ell_{A}^{\otimes} A=C_{A}^{\otimes} l_{A}^{0} E, \quad\left|A+C_{A}^{0} E\right|=0,
\end{aligned}
$$

$\mathrm{E}-\mathrm{is}$ the unitary matrix

In the latter case these relationships can be written as:

$$
\left(\ell_{B}^{(i)} \bar{X}\right), i+C_{B}^{0}\left(\ell_{B}^{0} \bar{X}\right), z=\left(\ell_{A}^{0} A \bar{X}\right)_{,} x^{0}+\left(\ell_{B}^{0} C\right)
$$

where $\ell_{\delta}^{0}$ is the $i-t h$ left eigenvector of the matrix $B$, and

$C_{B}(0)$ is its eigenvalue. Here:

$$
\ell_{B}^{Q} B=C_{B}^{0} l_{B}^{0} E, \quad\left|B+C_{B}^{Q} E\right|=0 \text {. }
$$

These relationships are also approximated following the Maccormac's technique and serve for calculation on the exterior layer the velocity and stress components in time not given by boundary conditions.

The corner points which are the intersection of the straight Iine $\mathrm{x}=$ const and $\mathrm{x}=$ const are calculated with the help of bicharacteristic relationships following the Maccormac technique. Here, on "predictor" step use is made of the first-type relationship (for $\ell_{A} O \bar{X}$ ) and on the "gorrector" step use is made of the relationship of the second type $\left(e_{B} \mathcal{O} \bar{X}\right)$.

The contact points belonging to the both pipes being welded are calculated with the help of the second-type bicharacteristic relationships with allowance for the continuity of the velocity and stress vectors on the area: $r=$ const.

For realization on the computer the mathematical model is organized following the module principle. In the main program there is organized the reduction of initial physical parameters (technological parameters of collision process), construction of the grid and realization of numerical procedure.

The analysis of the numerical solutions of the set program has made it possible to obtain the basic laws of the effect of technological parameters of the explosion-welding parameters on the changes in the geometry of the contact boundary between the materials being joined together and on the uniformity of the physical and mechanical properties of joints. The solution of this problem may be used in the technological analyses of quality characteristics in case of high-speed welding and treatment of cylindrical parts.

\section{REFERENCES}

1. Deribas A.A. Strengthening and explosion-welding physics. Novosibirsk. Nauka. 1980, $22.2 \mathrm{p}$.

2. Rozhdestvensky V.K., Yanenko N.N. Sets of quazi-linear equations. M. Nauka, 1978 .

3. Magometov-Kholodov. Grid-characteristic numerical methods. M. Nauka, 1988 . 